\title{
LA PASTORAL UNIVERSITARIA
}

\author{
UNIVERSITY MINISTRY
}

Gerardo Remolina Vargas*

\begin{abstract}
RESUMEN
En sintonía con la Constitución Apostólica "Ex Corde Ecclesiae" (1990) de Juan Pablo II, el autor subraya una de las características fundamentales de las Universidades Católicas, como es la de promover una auténtica integración del saber; de modo que fe y razón no están enfrentadas sino que son complementarias en esa búsqueda de la verdad que edifica al hombre y lo realiza plenamente. El autor argumenta a favor de una pastoral universitaria que ha de responder a las necesidades propias del ambiente en donde el diálogo entre fe y razón, fe y ciencia, fe y cultura ha de ocupar un lugar de primera importancia. La Universidad es el lugar privilegiado en donde ha de promoverse esa cultura de diálogo, donde las diferencias y pluralismos son aceptados para una confrontación que ayude a crear una mentalidad crítica, argumentativa, reflexiva y que conlleva al desarrollo integral de la persona.
\end{abstract}

\section{PALABRAS CLAVE:}

Pastoral universitaria, fe, razón, cultura, evangelización, diálogo, discernimiento.

\begin{abstract}
In consonance with the Apostolic Constitution "Ex Corde Ecclesiae" (1990) John Paul II, the author highlights one of the fundamental characteristics of Catholic Universities as is to promote a genuine integration of knowledge; so that faith and reason are not opposed but rather complementary in that search for the truth that edifies and realizes the man to the full. The author argues on behalf of a university ministry that has to respond to the needs of the environment where the dialogue between faith and reason, faith and science, faith and culture has to occupy a place of prime importance. The University is the privileged place to promote that culture of dialogue where differences and pluralisms are accepted for a confrontation that helps to create a critical, argumentative, reflective mind and leads to integral development of the individual.
\end{abstract}

\section{KEYWORDS:}

University Ministry, faith, reason, culture, evangelization, dialogue, discernment

Sacerdote y Past Rector de la Pontificia Universidad Javeriana de Colombia : gremolina@javeriana.edu.co 


\section{CONCEPTO Y ESPECIFICIDAD DE LAS DIVERSAS FORMAS DE PASTORAL}

Se concibe comúnmente la pastoral como el proceso mediante el cual se busca facilitar, propiciar, y fortalecer la vivencia cristiana mediante el encuentro con Dios y las demás personas. A su vez, se puede comprender también como el proceso de acompañamiento en la búsqueda y encuentro personal con Dios, en la persona de Cristo Jesús, mediado por la Iglesia. Desde esa perspectiva, comprenderá una serie de actividades de diverso orden: intelectual, afectivo, y social. De aquí que, la pastoral ha de adecuarse a cada tipo de persona, grupo, y situación social: por ejemplo, existe una pastoral social, parroquial, familiar, juvenil, de enfermos, universitaria. Cada una de estas formas de pastoral, tiene sus características propias y específicas.

La pastoral universitaria, si quiere ser tal, no puede convertirse en una pastoral parroquial, O familiar. La pastoral universitaria se da en una institución académica en la que sus miembros (profesores y estudiantes) están consagrados al cultivo del conocimiento y búsqueda de la verdad. En consecuencia, una pastoral universitaria ha de ser una pastoral de la inteligencia. Y es aquí donde podemos fallar y de hecho fallamos. Si bien es magnífico realizar en la Universidad actividades de tipo sacramental, talleres de oración, retiros, ejercicios espirituales, confirmaciones, preparación para el matrimonio, formación de grupos apostólicos, y otras actividades más que sin duda alguna propician y fortalecen la vivencia cristiana; estas son más propias de una pastoral parroquial. Mientras la pastoral universitaria no procure, como objetivo específico propio, el cultivo cristiano de la inteligencia, fallamos en lo fundamental, porque actuamos de espaldas a los intereses y propósitos centrales de los profesores y estudiantes universitarios.

Cinco son, a mi manera de ver, pero fundamentado en los documentos eclesiásticos- las actividades específicas de una pastoral universitaria: el diálogo fe y razón, el diálogo fe y ciencia, el diálogo fe y cultura, la integración de fe y vida en el contexto universitario, y la atención a las características existenciales de los miembros que componen la comunidad universitaria. La universidad no sólo es el ámbito privilegiado y el lugar natural para realizar esos diálogos, sino también para prestar un servicio de calidad que esté a la altura de quienes cultivan la inteligencia.

\section{LO ESPECÍFICO DE LA PASTORAL UNIVERSITARIA}

\subsection{El diálogo fe y razón}

Según la Constitución apostólica "Ex Corde Ecclesiae" (ECE) de S.S. Juan Pablo II , una de las características fundamentales de las Universidades católicas es la de promover la integración del saber, "de modo que se pueda ver más profundamente cómo fe y razón se encuentran en la única verdad" (...) de manera que se ponga en evidencia que "la investigación metódica en todos los campos del saber, si se realiza de una forma auténticamente científica y conforme a las leyes morales, nunca será una realidad contraria a la fe, porque las realidades profanas y las de la fe tienen su origen en el mismo Dios" (ECE, no. 17).

Y en este propósito de integración del saber en el diálogo fe y razón, se ha de buscar la ayuda de la teología para darle a las demás disciplinas "una 
perspectiva y una orientación que no están contenidas en sus metodologías" (ECE no. 19).

La sentencia de Anselmo de Cantórbery "La fe que busca entender, y el entender que busca la fe", ("fides quaerens intellectum, et intellectum quaerens fidem"), o la de Agustín "entiende para que creas y cree para que entiendas" ("Intellege ut credas; crede ut intellegas") deben realizarse en la Universidad Católica a través de una pastoral de la inteligencia.

\subsection{El diálogo fe y ciencia}

La Ciencia está en el centro de la Universidad, y la autoridad de la ciencia cobra un peso extraordinariamente grande, hasta el punto de que la ciencia suele asumirse como el criterio único de verdad, y socialmente sus conocimientos adquieren un carácter de dogma prácticamente infalible. Por ello, cuando los conocimientos científicos entran en conflicto con afirmaciones de la fe, o parecen entrar en contradicción con ella, la fe lleva siempre las de perder.

Así, por ejemplo, actualmente la existencia de Dios parece entrar en contradicción con las ciencias biológicas y con la verdad de la evolución (cfr. Richard Dawkins, "El espejismo de Dios"); las neurociencias pretenden reducir toda la actividad humana al juego de las neuronas negando la libertad humana, la existencia del espíritu y otros aspectos fundamentales para la fe cristiana (cfr. Mathew Alper, "Dios está en el cerebro" ); la física y la astrofísica explicarían la conformación del universo de manera casual y espontánea, negando toda explicación que acuda a la creación de un ser extraterrestre (cfr. Stephen Hawking, "El gran diseño"); la Psicología explica la religiosidad como el resultado de instintos frustrados (cfr. Freud, "Totem y
Tabú", "Moisés y el Monoteísmo"); y así éstas y otras ciencias, como la matemática (cfr. Pier Giorgio Oddifredi, "Caro Papa, ti scrivo") parecen excluir la existencia de Dios, fundamento de la fe cristiana.

Según la Constitución "Ex Corde Ecclesiae", "Un campo que concierne especialmente a la Universidad Católica es el diálogo entre pensamiento cristiano y ciencias modernas. (...) Dicho diálogo atañe tanto a las ciencias naturales como a las humanas, las cuales presentan nuevos y complejos problemas filosóficos y éticos." (ECE, n. 46)

No es posible pretender realizar en la Universidad una pastoral que permita el acercamiento a Dios y a Jesucristo por medio de la oración y de los sacramentos, mientras se viva a nivel intelectual una realidad totalmente opuesta, o al menos cargada de profundos interrogantes o prejuicios.

\subsection{El diálogo fe y cultura}

Según la misma Constitución, "La Universidad católica es el lugar primario y privilegiado para un fructuoso diálogo entre el Evangelio y la cultura" (n. 43).

Ahora bien, la cultura contemporánea ha experimentado cambios extraordinariamente profundos y radicales en sus principios, criterios y valores; en los puntos de interés, en sus fuentes inspiradoras y modelos de vida, en las costumbres, instituciones y formas de expresión; en comparación con las diversas expresiones culturales propias de la religiosidad cristiana de hace 50 años.

Algunos de los puntos determinantes son, por ejemplo: los referentes a la conformación de las subjetividades, el significado de la naturaleza humana y 
la persona, el sentido de la libertad y la responsabilidad, el de la naturaleza y ejercicio de la sexualidad, y muchos otros, como las instituciones del matrimonio y la familia.

Por otra parte las nuevas tecnologías de la información y la comunicación han creado una mentalidad del todo particular, especialmente entre los jóvenes, hasta producir los llamados avatares, con un cuerpo y una vida virtual tan real para ellos como nuestro cuerpo y nuestra vida espacial lo son para nosotros. Así se habla de la otra vida, del otro mundo, con un significado totalmente diferente al tradicional del cristianismo.

¿Cómo puede ser comprensible y acogida la fe cristiana en estos medios culturales, cuando ella se ha expresado hasta ahora en paradigmas hoy culturalmente obsoletos, y por consiguiente ininteligibles? Éste ha de ser el objetivo fundamental del diálogo fe y cultura.

Según el Papa Francisco, en su Exhortación Apostólica "Evangelii Gaudium" (n.132),

El anuncio [de la fe] a la cultura implica también un anuncio a las culturas profesionales, científicas y académicas. Se trata del encuentro entre la fe, la razón y las ciencias, que procura desarrollar un nuevo discurso de la credibilidad, una original apologética que ayude a crear las disposiciones para que el Evangelio sea escuchado por todos. Cuando algunas categorías de la razón y de las ciencias son acogidas en el anuncio del mensaje, esas mismas categorías se convierten en instrumentos de evangelización; es el agua convertida en vino. Es aquello que, asumido, no sólo es redimido sino que se vuelve instrumento del Espíritu para iluminar y renovar el mundo.

Y más adelante afirma:

Las Universidades son un ámbito privilegiado para pensar y desarrollar este empeño evangelizador de un modo interdisciplinario e integrador. Las escuelas católicas, que intentan siempre conjugar la tarea educativa con el anuncio explícito del Evangelio, constituyen un aporte muy valioso a la evangelización de la cultura, aun en los países y ciudades donde una situación adversa nos estimula a usar nuestra creatividad para encontrar los caminos adecuados.

\subsection{La Integración de vida y fe en el contexto universitario}

A través de su esfuerzo, la pastoral universitaria -como toda pastoral- ha de tender en último término a integrar la vida con la fe, a encarnar la fe en las actividades diarias, "con momentos significativos para la reflexión" (cfr. CEC nn. 38-39) y el encuentro personal con Dios en la oración y en los sacramentos; en el encuentro y atención a los hermanos, especialmente los más necesitados.

Benedicto XVI, en su discurso en la Universidad Católica de América, "Sobre la naturaleza y la identidad de la educación Católica hoy" (Washington, 17 de abril de 2008) se refiere a algunos rasgos fundamentales que ha de tener la Escuela Católica, y por consiguiente nuestras Universidades, que tocan de una u otra manera el tema pastoral. Señalaremos algunos de ellos: 
Según el Pontífice, la escuela católica debe ser un lugar para encontrar al Dios vivo en Jesucristo y suscitar el deseo de crecer en su conocimiento, comprensión y enseñanza, para llevar una vida marcada por todo lo que es bello, bueno y verdadero (cfr. n. 2). Debe ofrecer la posibilidad de "descubrir la verdad última sobre la propia vida y sobre el "fin de la historia", y guiar "tanto al docente como al estudiante hacia la verdad objetiva que, trascendiendo lo particular y subjetivo, apunta a lo universal y a lo absoluto" (n. 3). Ha de orientar a la esperanza, no obstante "los conflictos personales, la confusión moral y la fragmentación del conocimiento (...), fundándose en la unidad de la verdad y en el servicio a la persona y comunidad" (n. 3). Debe ayudar a realizar "el deseo de Dios de darse a conocer, y el innato deseo de cada ser humano de conocer la verdad", así como ayudar a "la búsqueda humana sobre el significado de la vida"; a comprender que "solo en el misterio del Verbo Encarnado se esclarece verdaderamente el misterio del hombre" (n. 6). Y ha de estar atenta a no atraer solo la inteligencia de los jóvenes, sino atender a su voluntad, clarificando la noción de libertad como la "facultad de «comprometerse con» y no como «la facultad de desentenderse des", animando a los jóvenes a "comprometerse con la vida eclesial" que nace de la fe (n. 8). En definitiva, a procurar que la educación lejos de ser una comunicación de datos fácticos, informativa, sea creativa y capaz de cambiar la vida, es decir, que sea performativa (n. 10).

\subsection{La idiosincrasia de la comunidad universitaria}

La pastoral universitaria ha de atender de manera especial a la peculiar idiosincrasia de quienes constituyen la comunidad académica que se quiere acompañar en el camino hacia Dios; estos son los estudiantes y profesores.

La gran mayoría de los estudiantes se halla en la edad de la adolescencia y primera juventud. Hoy nuestros estudiantes llegan cada vez más jóvenes a las aulas universitarias, ansiosos de vivir las nuevas experiencias que les brinda una aparente libertad, de menor dependencia y control de sus padres y educadores, y con un cierto sentido de autosuficiencia por haber alcanzado superar la primera etapa académica importante de sus vidas. Predomina en ellos el deseo afirmar su independencia y autonomía, tanto desde el punto de vista de su conducta como de su pensamiento. Por lo general, experimentan un rechazo a todo tipo de indoctrinación y de autoridad que toque lo íntimo de sus vidas y pretenda coartar su libertad con normas o prescripciones de comportamiento.

Pero experimentan al mismo tiempo el deseo y el respeto por la ciencia que van a adquirir y que será la herramienta de su profesión. La razón argumentativa comenzará a ser la brújula de su conocimiento y todo habrá de pasar por el filtro de la razón. En el mejor de los casos estarán dispuestos a revisar los principios y valores que les han infundido en el colegio y en la familia (si es que se les han infundido algunos), pero prefieren quizás prescindir simplemente de ellos. En la sociedad actual, una buena parte de los estudiantes, si no la mayoría, no ha tenido una buena formación religiosa, y carecerá, por consiguiente, de puntos de referencia para una posible vivencia cristiana de Dios.

Por su parte, los profesores experimentan el conflicto entre fe y ciencia, y ponen en tela de juicio el tradicional dogmatismo cristiano, que 
se percibe contrario a la razón, cargado de prejuicios y de errores históricos, científicos y políticos. La historia del cristianismo con sus innegables equivocaciones, y la historia de la ciencia con sus innegables logros, inclina para ellos claramente la balanza en sentido positivo hacia la ciencia. Las epistemologías "científicas" se constituyen en las únicas formas válidas de conocimiento y de conducta, y el conocimiento "científico" se constituye a su vez en valor apodíctico, hasta caer incluso en un nuevo dogmatismo: el científico.

\section{LA PASTORAL Y EVANGELIZACIÓN}

LA NUEVA

De acuerdo, una vez más, con la "Ex Corde Ecclesiae", "La misión primaria de la Iglesia es anunciar el Evangelio de manera tal que garantice la relación entre vida y fe tanto en la persona individual como en el contexto socio-cultural en que las personas viven, actúan y se relacionan entre sí" . (n. 48)

El papa Juan Pablo II, en su discurso inaugural de la IV Conferencia General del Episcopado Latinoamericano de Santo Domingo, en 1988 habló de la necesidad de realizar una "nueva evangelización" que él caracterizó con tres notas fundamentales: La nueva Evangelización ha de ser nueva en su ardor, nueva en sus métodos y nueva en su lenguaje. ${ }^{1}$

Quizás, y ojalá, exista verdaderamente el ardor. Pero después de casi 25 años ha sido muy difícil, por no decir imposible, percibir en la Iglesia los nuevos métodos y sobre todo el nuevo lenguaje. ¿No es, precisamente ésta una tarea "pastoral" de la Universidad Católica a través de sus facultades Teología o de los centros teológicos?

Quiero referirme a ese último aspecto del lenguaje en que se expresa la fe. Éste resulta cada vez más extraño y alejado del hombre de hoy; los grandes documentos eclesiásticos, sin duda alguna de extraordinario valor para alimentar la fe y el compromiso cristiano, son in-inteligibles y se caen de las manos, aun de los iniciados. La predicación suele rodar por encima de las personas como el agua, sin penetrar en el corazón; la palabra de Dios no sólo ha dejado de ser espada de dos filos que penetra hasta lo más profundo del alma y del espíritu, hasta lo más íntimo de la persona (Hebr. $4,12)$, sino que ya no les dice nada a los hombres y mujeres de hoy.

El jesuita flamenco Roger Laeners (2008) trata detalladamente el tema de "La fe en lenguaje de modernidad", y hace un análisis sumamente crítico y al mismo tiempo muy constructivo acerca de lo obsoleto del lenguaje entendido en sentido amplio, como diversas formas de expresión, en que pretendemos seguir expresando y comunicando nuestra fe. "El lenguaje de la tradición cristiana se ha vuelto un idioma extraño, una lengua para iniciados, accesible sólo para esa porción cada vez más pequeña de la población que todavía se maneja con las representaciones del pasado." (Laeners 2008, p. 11). Pero la Providencia de Dios no ha estado ausente, y la llegada al ministerio petrino del Papa Francisco (2013) nos ha dado ejemplos elocuentes de lo que es una evangelización nueva en

1 Será «nueva en su ardor» "si a medida que se va obrando, corroboráis más y más la unión con Cristo, primer evangelizador". "La evangelización será «nueva en sus métodos» si cada uno de los miembros de la Iglesia se hace protagonista de la difusión del mensaje de Cristo." "Para que la evangelización sea «nueva» también «en su expresión», debéis estar con los oídos atentos a lo que dice el Señor, esto es, siempre en actitud de escucha a lo que el mismo Señor puede sugerir en cualquier momento." 
su ardor, en su lenguaje y en sus métodos, al mismo tiempo que nos invita "a todos a ser audaces y creativos en esta tarea de repensar los objetivos, las estructuras, el etilo y los métodos evangelizadores de las propias comunidades." (EG 33). Obviamente, una de estas comunidades es la universitaria.

\section{PRINCIPIOS FUNDAMENTALES PARA LA PASTORAL DEL DIÁLOGO}

El diálogo en su sentido estricto no es un debate, ni una discusión, ni una negociación en donde haya un vencedor y un vencido, un ganador y un perdedor. Un diálogo es un proceso de mutuo enriquecimiento, en el que cada uno de los participantes pone a disposición de los demás toda la riqueza de su pensamiento y procura aceptar y asumir, con apertura total, toda la verdad de los demás.

El diálogo exige de entrada una actitud ética de honestidad tanto para manifestar todo el pensamiento, pues reservarse algo es restringir la posibilidad de enriquecimiento del otro, como la voluntad de cambiar los propios puntos de vista cuando la fuerza de los argumentos, o la razonabilidad, así lo impongan. El diálogo, utilizando una expresión de Karl Jaspers, es un juego con cartas abiertas, una lucha con intercambio de armas, un combate amoroso, que tendrá éxito únicamente si ambos participantes, salen vencedores; la derrota de uno de ellos es la derrota de ambos, y la victoria de uno es la victoria de todos. En el diálogo no se trata de renunciar a los propios principios, ni de defenderlos a ultranza, pero sí de exponerlos con toda su fuerza y validez de los argumentos. Con relación al diálogo pastoral, vale la pena destacar algunos principios fundamentales que es necesario poner de entrada sobre la mesa. Tales principios son, a mi manera de ver, los siguientes:

\subsection{Naturaleza trascendente del conocimiento humano}

El conocimiento humano es un dinamismo irrefrenable e insobornable en búsqueda de la verdad. Ésta consiste en la aprehensión de la realidad, del ser. Existe una relación intrínseca entre conocer y ser, entre conocer y realidad. Cuando el conocer aprehende la realidad, tenemos la verdad. Su objetividad se realiza cuando, cumplido correctamente todo el proceso y la secuencia de las operaciones cognoscitivas, se dan las condiciones necesarias para afirmar o negar una determinada realidad. Nuestro conocimiento es objetivo cuando la realidad que afirmamos no es únicamente el fruto de nuestra actividad subjetiva, sino del encuentro de ésta con una realidad independiente de ella. Por otra parte, el conocimiento humano es un dinamismo siempre insatisfecho, e incoercible, y por ello persigue su objeto de manera incansable; nunca puede detenerse, porque detrás de cada encuentro, de cada respuesta, surge una nueva pregunta, un nuevo interrogante en una especie de "progresión al infinito". En otras palabras, el conocimiento humano es siempre trascendente, va siempre "más allá", no se detiene, y no es posible poner límites a sus preguntas, pues esto sería mutilarlo e ir en contra de la naturaleza misma de una Universidad. Ésta, por su misma naturaleza, ha de estar siempre abierta a cualquier interrogante, incluido el interrogante de la Transcendencia con mayúscula.

\subsection{Unidad de la verdad, y unidad de fe y saber}

De otro lado, la verdad es una, porque una es la realidad en su totalidad, no obstante sus diferentes niveles y su infinita multiplicidad y variedad. Según el Concilio Vaticano II (GS, No.36): 
La investigación metódica en todos los campos del saber, si está realizada de una forma auténticamente científica y conforme a las normas morales, nunca será en realidad contraria a la fe, porque las realidades profanas y las de la fe tienen su origen en un mismo Dios. Más aún, quien con perseverancia y humildad se esfuerza por penetrar en los secretos de la realidad, está llevado, aun sin saberlo, como por la mano de Dios, quien sosteniendo todas las cosas, da a todas ellas el ser. Son, a este respecto, de deplorar ciertas actitudes que por no comprender bien el sentido de la legítima autonomía de la ciencia, se han dado algunas veces entre los propios cristianos; actitudes que, seguidas de agrias polémicas, indujeron muchos a establecer una oposición entre la ciencia y la fe.

Lo anterior nos lo ha recordado recientemente el Papa Francisco en su Exhortación Apostólica "Evangelii Gaudium" (nn. 242 y 243), cuando dice:

La fe no le tiene miedo a la razón; al contrario, la busca y confía en ella, porque «la luz de la razón y la de la fe provienen ambas de Dios» y no pueden contradecirse entre sí. (...) La Iglesia no pretende detener el admirable progreso de las ciencias. Al contrario, se alegra e incluso disfruta reconociendo el enorme potencial que Dios ha dado a la mentehumana. Cuandoeldesarrollo de las ciencias, manteniéndose con rigor académico en el campo de su objeto específico, vuelve evidente una determinada conclusión que la razón no puede negar, la fe no la contradice.

\subsection{Diversas formas de conocimiento y de acceso a la verdad}

La ilustración y la modernidad han privilegiado la razón como única forma posible de acceso a la verdad. De ahí que la ciencia, en la que predomina la razón, se haya constituido en nuestra sociedad en el criterio último de verdad. Y si bien, la razón y la ciencia han de ocupar, y de hecho ocupan un lugar de primera importancia, ellas no agotan el conocimiento y el saber. Utilizando los conceptos kantianos, no sólo existe el uso especulativo de la razón, sino también el uso práctico del conocimiento ético, y el uso del juicio que conoce lo bello y lo amable de la realidad.

El Papa Francisco (2013) advierte en su Evangelii Gaudium a este propósito que:

"El cientismo y el positivismo se rehúsan a «admitir como válidas las formas de conocimiento diversas de las propias de las ciencias positivas». La Iglesia propone otro camino, que exige una síntesis entre un uso responsable de las metodologías propias de las ciencias empíricas y otros saberes como la filosofía, la teología, y la misma fe, que eleva al ser humano hasta el misterio que trasciende la naturaleza y la inteligencia humana" (EG 242).

Alberto Parra, S.J., en su manuscrito "Anotaciones sobre la Pastoral Educativa Universitaria", anota que además del conocimiento científico de la razón que "explica" la realidad, existe el conocimiento del intelecto que exige la comprensión del "sentido" de esa misma realidad. Es que la ciencia exige del conocimiento explicación e intelección de los objetos (erklären); en 
tanto que los discursos de sabiduría son espacio vital para la comprensión de los sujetos (verstehen) en situación, abiertos y referidos en su preguntar a textos de tradición y ello para animar de modo constante los grandes pretextos éticos de liberación y de justicia, de fraternidad y de consensos, de progreso sostenible y de la paz estable"; y él mismo refiere que Lyotard, en su obra La Condición Postmoderna, muestra con incisión que la razón moderna entronizó de tal modo los lenguajes y métodos de la ciencia, que se sustrajo con desdén a los lenguajes de la sabiduría, a la tradición, a la cultura, a la lógica de la razón simbólica. Y ello con un balance universal deficitario de sabiduría en sociedades ilustradas, altamente tecnificadas y desarrolladas. Aquello que no fue razón ilustrada fue tenido como mito, ensoñación y quimera.

La sabiduría, por el contrario, es el conocimiento intuitivo, intelectivo y afectivo, que va más allá de los límites de la razón. La sabiduría busca comprender el sentido profundo de la existencia humana; es la capacidad de comprender y juzgar acertadamente de los seres humanos, de las cosas, de los acontecimientos y de la historia, del entorno natural y de lo que lo trasciende.

El famoso escritor y semiólogo italiano, Umberto Eco, autor de la novela "El nombre de la Rosa", que lo llevó a la fama, en el discurso que pronunció al recibir el doctorado "Honoris causa" que le concedió la Universidad Hebrea de Jerusalén, recordaba el famoso pasaje del capítulo 19 del Libro primero de los Reyes $(1,19)$. Allí, el profeta Elías, llamado a la presencia del Señor en la gruta del monte Horeb, siente pasar el fuerte viento de las montañas que quebraba las rocas, y la conmoción de la tierra y del aire, y el paso del fuego devorador, y concluye que el Señor no está ni en el viento, ni en el tumulto, ni en el fuego, sino en la brisa suave, en la tenue animación del espíritu. $\mathrm{Y}$ entonces comenta el novelista Eco (2002):

"No se puede encontrar a Dios en el ruido, Dios sólo se revela en el silencio. Dios no está nunca en los medios de comunicación, Dios no está nunca en las primeras páginas de los periódicos, Dios no está nunca en la televisión, Dios no está nunca en Broadway. Él estaba en el alma de Elías, Dios estaba en Qumram, estaba en los monasterios benedictinos de la Edad Media, estaba en los guetos españoles donde los primeros cabalistas experimentaban las infinitas combinaciones de las letras de la Torá. Dios está donde no hay barullo."

"Esta máxima -continúa el autortambién es válida para quien no cree en Dios, pero cree que en alguna parte hay una Verdad que descubrir. La Verdad no se encuentra en el tumulto, sino más bien en una búsqueda silenciosa. En el trasiego de hoy los lugares del silencio permanecen y siguen siendo las universidades. Sin embargo, son pocos los lugares en los que es posible la comparación racional entre diversas visiones del mundo." (Eco, 12-06-2002).

Nosotros podemos preguntarnos: ¿Es realmente la Universidad, y muy especialmente la Universidad católica ese lugar privilegiado para la búsqueda de la verdad y de la sabiduría?

\section{CARACTERÍSTICAS DE UNA UNIVERSIDAD CATÓLICA}

El Papa Francisco, en su reciente visita pastoral a la Universidad de Cagliari (Cerdeña, 22 de septiembre de 2013) describe "La Universidad como lugar de elaboración y transmisión del saber, de formación a la «sabiduría» en el sentido 
más profundo del término, de educación integral de la persona. Y en esa dirección ofreció algunos breves puntos sobre los cuales reflexionar:

\subsection{La Universidad como lugar de discernimiento}

"Es importante leer la realidad, mirándola a la cara. Las lecturas ideológicas parciales no sirven, alimentan solamente la ilusión y la desilusión. (...) Cada crisis, también la actual, es un paso, un trabajo de parto que comporta fatiga, dificultad, sufrimiento, pero que lleva en sí el horizonte de la vida, de una renovación, lleva la fuerza de la esperanza. Y ésta no es una crisis de «cambio»: es una crisis de «cambio de época». Es una época la que cambia. No son cambios de época superficiales. (...) El discernimiento no es ciego, ni improvisado: se realiza sobre la base de criterios éticos y espirituales, implica interrogarse sobre lo que es bueno, la referencia a los valores propios de una visión del hombre y del mundo, una visión de la persona en todas sus dimensiones, sobre todo en la espiritual trascendente; no se puede considerar jamás a la persona como «material humano»."

\subsection{La Universidad como lugar de (sabiduría)}

"La Universidad como lugar de «sabiduría» tiene una función muy importante en formar al discernimiento para alimentar la esperanza (...) Hacer discernimiento significa no huir, sino leer seriamente, sin prejuicios, la realidad."

\subsection{La Universidad como lugar en que se elabora la cultura de la proximidad}

"Esta es una propuesta: cultura de la cercanía. El aislamiento y la cerrazón en uno mismo o en los propios intereses jamás son el camino para devolver la esperanza y obrar una renovación, sino que es la cercanía, la cultura del encuentro. (...) La Universidad es el lugar privilegiado en el que se promueve, se enseña, se vive esta cultura del diálogo, que no nivela indiscriminadamente diferencias y pluralismos -uno de los riesgos de la globalización es éste- , ni tampoco los lleva al extremo haciéndoles ser motivo de enfrentamiento, sino que abre a la confrontación constructiva. Esto significa comprender y valorar las riquezas del otro, considerándolo no con indiferencia o con temor, sino como factor de crecimiento."

\subsection{La Universidad como lugar de formación a la solidaridad}

"La palabra solidaridad no pertenece solo al vocabulario cristiano, es una palabra fundamental del vocabulario humano. Como dije hoy, es una palabra que en esta crisis corre el riesgo de ser suprimida del diccionario. (...) No hay futuro para ningún país, para ninguna sociedad, para nuestro mundo, si no sabemos ser todos más solidarios. Solidaridad por lo tanto como modo de hacer historia, como ámbito vital en el que los conflictos, las tensiones, también los opuestos alcanzan una armonía que genera vida."

\section{DIÁlOGOS FE-RAZÓN, FE- CIENCIA, FE-CULTURA}

Para concluir, deseo traer a la memoria, algunos diálogos recientes entre fe y razón, fe y ciencia, fe y cultura que pueden no solo ilustrarnos sobre el profundo respeto y seriedad con que han de afrontarse las personas que piensan distinto y sus objeciones, sino también animarnos a emprender diálogos semejantes en nuestra pastoral universitaria. 


\section{1 ¿En qué creen los que no creen? Un diálogo sobre la Ética en el fin del Milenio": Diálogo epistolar entre Carlo María Martini y Umberto Eco (1997).}

Al lanzar su pregunta al novelista y semiólogo Umberto Eco sobre los fundamentos de la ética de los nocreyentes, Martini "no pretendía -según él mismo lo expresa- ni «enseñar» ni «disertar» ni «polemizar», sino principalmente «interrogar», e interrogar para saber, para comprender cómo un laico sustenta teóricamente el carácter absoluto de sus principios morales. Por el interés que suscitó la pregunta, el diálogo se abrió, más allá de los dos dialogantes iniciales, a otros seis personajes del mundo intelectual. Y según el mismo Martini (1997), comenta:

"He podido captar en algunas respuestas (sobre todo en las aparecidas aquí y allá en la prensa, en realidad, más que en las de las seis intervenciones) cierta vena polémica y cierto esfuerzo de «apologética laica». He podido captar también cierta facilidad para simplificar la doctrina y la tradición cristiana a propósito de la ética, con síntesis en las cuales no leo mi pensamiento. Por ello me animo a dedicar al asunto algunas palabras más. Lo que más agradezco, de hecho, a los participantes en el debate es su estímulo para una reflexión común sobre el sentido del deber, sobre la pureza de la vida moral, sobre los ideales éticos que en cierto modo todos sentimos o en los que quisiéramos inspirarnos" (Eco, 1997, p. 53).

\subsection{Encíclica "Fides et ratio" de Juan Pablo II, 2008}

un diálogo, es una invitación a procurar el diálogo entre fe y razón, entre revelación y filosofía, pues ellas "son como las dos alas con las cuales el espíritu humano se eleva hacia contemplación de la verdad" (No. 1). La búsqueda y encuentro de la verdad es la preocupación central de la Encíclica, porque, según el Pontífice, la verdad ha sido y sigue siendo la preocupación fundamental de la vida y de la historia de la humanidad. En esta búsqueda apasionada de la verdad, Juan Pablo II defiende la capacidad de la razón humana para conocer la verdad, y pide que la fe y la filosofía vuelvan a encontrar su unidad profunda.

Hay un doble orden de conocimiento, distinto no sólo por su principio, sino también por su objeto; por su principio, primeramente, porque en uno conocemos por razón natural, y en otro por fe divina; por su objeto también porque aparte de aquellas cosas que la razón natural puede alcanzar, se nos proponen para creer misterios escondidos en Dios de los que, a no haber sido divinamente revelados, no se pudiera tener noticia. (FR, $n^{\circ} .9$ )

Así pues, la Revelación introduce en nuestra historia una verdad universal y última que induce a la mente del hombre a no pararse nunca; más bien la empuja a ampliar continuamente el campo del propio saber hasta que no se dé cuenta de que no ha realizado todo lo que podía, sin descuidar nada. Nos ayuda en esta tarea una de las inteligencias más fecundas y significativas de la historia de la humanidad, a la cual justamente se refieren tanto la filosofía como la teología." (FR n 14). "No hay, pues, motivo de competitividad alguna 
entre la razón y la fe: una está dentro de la otra, y cada una tiene su propio espacio de realización". (FR $\left.\mathrm{n}^{\circ} 17\right)$

\section{3 "Querido Papa, te escribo". Ciencia y Ciencia-ficción. Diálogo entre el matemático italiano Piergiorgio Odifreddi y Benedicto XVI, Papa Emérito.}

La editorial italiana Mondadori, había publicado en el 2011 un libro del famoso matemático italiano, Piergiorgio Odifreddi, titulado "Caro Papa, ti scrivo". En él, el autor cuestiona las tesis de Benedicto XVI en su libro "Introducción al cristianismo", y la calidad científica de la teología, calificada en varios lugares como" "ciencia ficción". Desde la misma portada, el libro se presenta como una "luciferina introducción al ateísmo". Sin embargo, después de la respuesta del Papa, Odifreddi reconoció que la fe y la doctrina de Benedicto XVI, a diferencia de otros, eran lo suficientemente coherentes y sólidas como para poder afrontar perfectamente las dificultades y sostener ataques frontales.

El 24 de septiembre de 2013, el Papa emérito respondió al matemático con una extensa carta ${ }^{2}$ en la que comienza por afrontar la calificación que él hace de la teología como "ciencia-ficción", haciendo cuatro precisiones muy concretas:

a) "Es correcto afirmar que 'ciencia' en el sentido más estricto de la palabra lo son solo las matemáticas, mientras yo he aprendido de usted -dice el Papaque sería necesario distinguir todavía entre aritmética y geometría. En todas las materias específicas la científica tiene cada vez su propia forma, según la particularidad de su objeto. Lo esencial es que aplique un método verificable, excluya el arbitrio y garantice la racionalidad en las respectivas modalidades".

b) En segundo lugar "usted debería por lo menos reconocer que, en el ámbito histórico y en el del pensamiento filosófico, la teología ha producido resultados duraderos".

c) En tercer lugar, es importante tener presente que "una función importante de la teología es la de mantener la religión unida a la razón y la razón a la religión. Ambas funciones son de esencial importancia para la humanidad". $\mathrm{Y}$ en este punto Ratzinger recuerda que en su diálogo con Habermas "he mostrado que existen patologías de la religión y -no menos peligrosas - patologías de la razón. Ambas necesitan la una de la otra, y tenerlas continuamente conectadas es una tarea importante de la teología".

d) Por último, extendiéndose mucho más que en los puntos anteriores, Benedicto XVI expresa que "la «fantaciencia» existe en el ámbito de muchas ciencias" y hace referencias a las teorías que Odifreddi expone sobre el inicio y el fin del mundo en Heisenberg, Schrödinger etc., que podría diseñarse "como «fantaciencia» en el buen sentido: son visiones y anticipaciones, para alcanzar un verdadero conocimiento, pero son, de hecho, solamente

2 https://www.google.com/\#q= piergiorgio + odifreddi + benedicto + xvi 
imaginaciones con las que buscamos acercarnos a la realidad".

En cuanto a las afirmaciones relativas al carácter histórico de la persona de Jesús, Ratzinger invita al matemático a leer los cuatro volúmenes que sobre el tema escribieron Martin Hengel y María Schwemer, "un ejemplo excelente de precisión histórica y de amplísima información histórica". Y En la última parte de su carta, Benedicto XVI señala que "mi crítica sobre su libro es en parte dura. Pero del diálogo forma parte de la franqueza; solo así puede crecer el conocimiento".

\section{Los diálogos de Scalfari y el Papa Francisco}

Más difusión han tenido, sin duda alguna, los diálogos sostenidos entre el Papa Francisco y el fundador del diario italiano La Reppublica, Eugenio Scalfari, quien se confiesa abiertamente "no creyente", "pero interesado y fascinado por la predicación de Jesús de Nazaret". El 7 de julio de 2013, Scalfari había formulado en el editorial de su diario una serie de preguntas al Papa Francisco acerca de la reciente Encíclica "Lumen Fidei", y las había ampliado un mes más tarde, el 7 de agosto, en el mismo diario.

El Papa responde "con profunda cordialidad" (son sus palabras) a las preguntas formuladas por Scalfari en una larga carta enviada el 11 de septiembre de 2013. En ella constata que paradójicamente a lo largo de la modernidad la luz de la fe cristiana, "ha sido calificada como la oscuridad de la superstición que se opone a la luz de la razón", y afirma que "Ahora ha llegado el momento, y el Vaticano II ha inaugurado justamente la estación de un diálogo abierto y sin prejuicios que vuelva a abrir las puertas para un serio y fructífero encuentro".

Y retomando el número 34 de la "Lumen fidei" (2013), subraya que "está claro que la fe no es intransigente, sino que crece en la convivencia que respeta al otro. El creyente no es arrogante; por el contrario, la verdad lo hace humilde, consciente de que, más que poseerla nosotros, es ella la que nos abraza y nos posee. Lejos de ponernos rígidos, la seguridad de la fe nos pone en camino, y hace posible el testimonio y el diálogo con todos". Y consecuente con ello, el Papa califica sus reflexiones "como una respuesta tentativa y provisional, pero sincera y confiada", e invita a Scalfari a "andar una parte del camino juntos."

La carta del Papa Francisco, -escribe Scalfari- ha suscitado en mí, en nuestro Director Ezio Mauro y en todos los colegas una gran emoción. Pienso que la misma emoción la han tenido todos lo que la han leído (...) Leyendo las palabras del Papa, nuestro pensamiento es llamado y estimulado a reflexionar ante la concepción del todo original que el Papa Francisco expresa sobre el tema «fe y razón», uno de los ejes cardinales de la arquitectura espiritual, religiosa y teológica de la Iglesia. Pero no solo de la Iglesia: la cultura moderna de Occidente nace exactamente de ese tema y el Papa Francisco lo recuerda en su carta "Lumen Fidei" (2013.

Como es sabido, el diálogo se reanudó el $1^{\circ}$ de octubre en la Casa de Santa Marta, después de una invitación personal del Papa:

"Ya estoy aquí (narra Scalfari). El Papa entra y me da la mano, nos sentamos. El Papa sonríe y me dice: «Alguno de mis colaboradores que lo conoce me ha dicho que usted intentará convertirme». Es un chiste le respondo. También mis amigos piensan que usted 
querrá convertirme. Sonríe de nuevo y responde: «El proselitismo es una solemne tontería, no tiene sentido. Es necesario conocerse, escucharse y hacer crecer el conocimiento del mundo que nos rodea. A mí me pasa que después de un encuentro quiero tener otro porque nacen nuevas ideas y se descubren nuevas necesidades. Esto es importante, conocerse, escuchar, ampliar el cerco de los pensamientos. El mundo está lleno de caminos que se acercan y alejan, pero lo importante es que lleven hacia el "Bien"».

Otros diálogos de interés pueden ser el de Ratzinger-Habermas sobre Política $y$ Religión, Fe y Razón, tenido en la Academia Católica de Baviera en enero de 2004, y el de Ratzinger con el filósofo y periodista Paolo Flores d'Arcais, ¿Dios existe?.

He querido traer a colación estos diálogos, porque su ejemplo nos permite captar el sentido profundo del diálogo pastoral que es necesario establecer en nuestras universidades. No se trata de polemizar, ni de hacer apologética. Se trata principalmente de interrogar para saber, para estimular la reflexión común, en actitud sincera, abierta, humilde y sin prejuicios que nos permita "andar una parte del camino juntos".

\section{REFERENCIAS:}

ECO, U. (1997) ¿En qué creen los que no creen. Un diálogo sobre la ética en el fin del milenio. Diálogo epistolar entre Carlo María Martini y Umberco Eco. Madrid: Temas de hoy.

ECO, U. (2002) "La fuerza de la cultura podrá evitar el choque de las civilizaciones". En el Diario "El País", Edición Impresa. Opinión, Miércoles
12 de junio.

FRANCISCO, Papa (2013) Carta Encíclica "Lumen Fidei", sobre la Luz de la Fe. Roma

FRANCISCO, Papa (2013) Exhortación Apostólica "Evangelii Gaudium", sobre el anuncio del evangelio en el mundo actual. Roma.

JUAN PABLO II (1990) Constitución apostólica Ex corde ecclesiae. Roma.

JUAN PABLO II (1998) Carta Encíclica Fides et Ratio, sobre la relación entre razón y fe. Roma.

LAENERS, R. (2008) "Otro Cristianismo es posible. Fe en lenguaje de modernidad". Quito: Editorial Abya Yala.

LENOIR, F. (2005) Las metamorfosis de Dios. La nueva espiritualidad occidental. Madrid, Alianza Editorial.

MARTIN VELASCO, J. (1993) El malestar religioso de nuestra cultura. 2 ed. Madrid, paulinas.

OBIOLS, G. (2006) Adolescencia, posmodernidad y escuela. La crisis de la enseñanza media. Buenos Aires: Noveduc.

RATZINGER, J. (1995) Ser cristiano en la era neopagana. Encuentro, Madrid.

RATZINGER, J. (2006) El Dios de la fe y el Dios de los filósofos. Encuentro, Madrid.

RATZINGER, J. y FLORES, P. (2008) ¿Existe Dios? Madrid: Espasa Calpe. 